\title{
Personality Traits, Medication Beliefs \& Adherence to Medication among Diabetic Patients Attending the Diabetic Clinic in a Teaching Hospital in Southwest Nigeria
}

\author{
Adeyinka Adeniran1*, Modupe Akinyinka1, Kikelomo 0. Wright'1, Omowumi Q. Bakare1, \\ Olayinka O. Goodman', Yetunde A. Kuyinu1, Olumuyiwa O. Odusanya1, Akin Osibogun² \\ ${ }^{1}$ Department of Community Health and Primary Health Care, College of Medicine, Lagos State University, Lagos, \\ Nigeria \\ ${ }^{2}$ Department of Community Health and Primary Care, College of Medicine, University of Lagos, Lagos, Nigeria \\ Email: *yinkadeniran@yahoo.com
}

Received 28 October 2015; accepted 21 November 2015; published 24 November 2015

Copyright (C) 2015 by authors and Scientific Research Publishing Inc.

This work is licensed under the Creative Commons Attribution International License (CC BY). http://creativecommons.org/licenses/by/4.0/

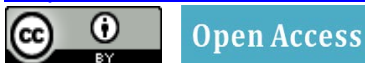

\begin{abstract}
Background: Non-adherence to drug therapy is an important cause of treatment failure among patients with chronic conditions like diabetes. Previous researches have presented associations among personality traits, medication beliefs and adherence to long-term medication treatment in individuals with different chronic diseases. However, there is limited knowledge about associations among personality traits, medication belief and adherence to diabetic treatment in Africa. It was on this basis that this study was undertaken to assess the personality traits and personal beliefs of patients on medication for Diabetes Mellitus (DM) and to also assess adherence to treatment. Methodology: This study was a descriptive cross sectional study. Using a systematic random sampling technique, 223 patients attending the diabetic clinic of Lagos State University Teaching Hospital, Lagos were selected over a period of 12 weeks. Patients were interviewed using the Big Five-factor Personality Inventory, Medication Belief Questionnaire and the Medication Adherence Report Scale. Data were statistically analyzed using descriptive statistics, Student's t-tests, Chi Square Tests and Pearson's correlations analysis. Results: Non-adherence was estimated to be 40.8\%. Non-adherent respondents had lower mean score of neuroticism personality traits compared to adherent respondents. Pearson's correlation analysis showed a weak negative relationship between neuroticism personality trait and adherence behaviour $(P<0.05)$. There was also a statistically significant weak correlation $(r=0.1)$ between specific concern medication belief and adherence to medication among respondents in the study $(P<0.05)$. Conclusion: Personality traits
\end{abstract}

How to cite this paper: Adeniran, A., Akinyinka, M., Wright, K.O., Bakare, O.Q., Goodman, O.O., Kuyinu, Y.A., Odusanya, O.O. and Osibogun, A. (2015) Personality Traits, Medication Beliefs \& Adherence to Medication among Diabetic Patients Attending the Diabetic Clinic in a Teaching Hospital in Southwest Nigeria. Journal of Diabetes Mellitus, 5, 319-329.

http://dx.doi.org/10.4236/jdm.2015.54039 
of diabetic patients can influence their adherence to treatment. Patients with neuroticism personality trait and specific concern medication belief tend to be non-adherent to medication. Healthcare providers should therefore pay more attention to the personality traits and medication beliefs of patients in providing effective management for diabetic patients.

\section{Keywords}

\section{Personality Traits, Medication Beliefs, Adherence to Medication, Diabetes}

\section{Introduction}

Chronic diseases such as diabetes mellitus require lifelong drug treatments which affect patients in many ways bringing about various restraints. Diabetes is a complex disorder requiring the continuous attention of both healthcare providers and patients. Even though individuals with diabetes mellitus (DM) have been shown to have an impact on treatment outcome by participating in the disease management, adherence to these activities has been found to be poor, especially when looking at long-term changes [1]. In particular, non-adherence to drug therapy is an important cause of treatment failure and a consequence of many chronic diseases, with a reported $30 \%-80 \%$ of non-compliance among patients with Acquired Immune Deficiency Syndrome (AIDS), tuberculosis, hypertension and dyslipidaemia [2].

The current prevalence of DM in Nigeria is in the region of $8 \%-10 \%$ [3]. Three types are frequently recognised, namely, Type 1 DM (T1DM), Type 2 DM (T2DM) and gestational diabetes. T2DM is the most commonly documented form, accounting for about $90 \%-95 \%$ of all cases of DM in most endocrine clinics [4]. Adherence can be defined as the extent to which the patient's behaviour matches the agreed recommendations from the prescriber and the prescription. Factors associated with non-adherent behaviour include socioeconomic factors, therapy-related factors, condition-related factors, health care system factors and patient-related factors such as personality traits and patients' beliefs about medicines [5]. Generally, only about half of all patients on medication are actually adherent $[4]$.

Among 150 diabetic patients sampled in New York City, 28\% did not adhere to medications. Their beliefs about DM and the medications were significantly associated with the non-adherent behavior [6]. In Malaysia, a study conducted in a Primary Health Clinic (PHC) among 557 diabetic patients reported over half (53\%) of the participants as being non-adherent to medication, with age, medication knowledge and co-morbidities being predictors of non-adherence [7]. In Nigeria, a study on the adherence to anti-diabetic drug therapy and selfmanagement practices among type- 2 diabetics conducted in the South west revealed that $59 \%$ of patients were not adherent due to various reasons including finance, side effects and perceived inefficacy of the anti-diabetic drugs [8].

Adherence rates to both insulin and oral hypoglycaemic medications as low as $26.4 \%$ were reported among $220 \mathrm{DM}$ patients in a study conducted in Ilorin, Nigeria [9]. An adherence rate of $72.5 \%$ to oral hypoglycaemic medications was however reported among 120 patients attending the family medicine clinic of a Federal Medical Centre in Eastern Nigeria [10].

Although there is a paucity of local data about personality trait, patient medication beliefs and adherence, it has been documented that associations among patients' personality trait, personal beliefs about medicines and self-reported adherence to medications exist [5] [11]-[14]. However, data from older studies revealed that medication beliefs and personality trait appeared to be more powerful predictors of reported adherence than the clinical and socio-demographic factors [12]-[14].

Adherent behaviour is said to be associated with personal beliefs about the specific prescribed medication and its necessity for controlling illness balanced against concerns about the possible negative effects of medications [15].

Measuring adherence to medications among DM patients would provide information about adherence rates in this environment. In addition, assessing associations among adherence, patients' personality traits and medication beliefs can provide essential details about how these factors predict adherence serving as an essential tool for physicians, other health care providers, and public health practitioners. This can aid the counselling and effective communication with patients for improved medication and therapy adherence, better treatment outcomes and pre- 
vention of complications.

The general objective of this study was to assess adherence to medications among diabetic patients attending the diabetes clinic of a Tertiary Health Institution. The specific objectives were to assess the personality traits and personal beliefs of patients on medication for DM, to determine adherence to medication for DM among the patients, and to identify any association among personality traits, personal beliefs about medication and adherence to therapy among the patients.

\section{Materials and Methods}

Lagos State is located in South-Western Nigeria and lies on longitude $3^{\circ} 24^{\prime} \mathrm{E}$ and latitude $6^{\circ} 27^{\prime} \mathrm{N}$. Lagos State has an estimated population of 15 million people, is made up of 20 Local Government Areas, and 37 Local Council Development Areas. Ikeja, the capital of Lagos State is urban, with an area of about $46.2 \mathrm{sq} \cdot \mathrm{Km}$ and a population of about 313,196 inhabitants [16].

Lagos State University Teaching Hospital, Ikeja (LASUTH) was commissioned as a General Hospital in 1955, as it was originally a Cottage Hospital and was subsequently upgraded to a Teaching Hospital in 2001 [17]. It is a multi-specialist hospital with a total bed complement of 484 and a staff complement of 1686 including 93 honorary consultants [18]. The premise also houses the Lagos State University College of Medicine (LASUCOM). The hospital runs several clinics such as the Chest clinic, Immunization clinic, Pediatrics clinic, Surgical clinics, Obstetrics and Gynecology clinics, General out-patient clinics, and the Medical clinics, including the Diabetes clinic where patients who are being managed for DM are attended to.

\subsection{Measurement of Adherence}

Measurement of adherence can only be an estimate of a patient's actual behavior. Methods used include subjective ones such as provider and patient reports of adherence, use of standardized patient-administered questionnaires (General and Specific), while objective methods include counting of remaining dosage units, electronic monitoring device (Medication Event Monitoring System, MEMS) and the use of pharmacy prescription records [4]. No single method is considered optimal and feasible combinations are expected to provide more accurate information about adherence [4]. In Nigeria, pharmacy records may be inaccurate and misleading as patients patronize several pharmacies, MEMS would be financially unfeasible and so standardized patient-administered questionnaires are considered the most appropriate in these circumstances.

\subsection{Assessment of Personality Traits}

In Psychology, the taxonomy of personality traits are collectively called the Big Five [19]. The Big Five Factors or personality traits are five broad domains or dimensions of personality that are used to describe human personality which are able to account for different traits in personality without overlapping. It has been shown that the Big Five personality traits show consistency in interviews, self-descriptions and observations and appear to be found across a wide range of participants of varying ages and cultures [20]. The five factors are openness, conscientiousness, extraversion, agreeableness, and neuroticism. These traits may be measured in a variety of ways including the use of Big Five Inventory (BFI), the International Personality Item Pool (IPIP), the Big Five aspect scales (BFAS), the Big Five mini markers, Ten Item Personality Inventory (TIPI), the NEO Personality Inventory-Revised (NEO PI-R) and the NEO Five Factor Inventory (NEO FFI), the last 2 being commercial [19]. However, many of these methods have too many items to be practicable in a clinical setting, and the very short TIPI would result in some measurement tradeoffs [20]. The BFI which is a 44-item inventory that measures an individual on the Big Five Factors (dimensions) of personality and further sub divides each factor into personality facets was therefore adopted as most appropriate for this study [21].

\subsection{Study Population}

The study population was selected from the diabetic patients receiving medications at the Diabetes Clinic of LASUTH.

\subsection{Study Design}

The study is cross sectional and descriptive with the use of structured interviewer-administered questionnaires. 


\subsection{Sample Size}

Using an appropriate formula, the required sample size for the study was determined at 218 .

\subsection{Sampling Method}

Patients were selected using systematic random sampling method. A sampling interval of 3 was derived from 810 (average population of patients in 3 months) $/ 242$ (calculated sample size). Therefore, every $3^{\text {rd }}$ patient who met the inclusion criteria was selected until the sample size had been attained.

\subsection{Inclusion Criteria}

1) Patients must have been on anti-diabetic medications for at least 6 months.

2) Patients must be aged 15 or above.

\subsection{Exclusion Criteria}

Patients who are critically ill were excluded from the study.

\subsection{Survey Instruments}

An interviewer-administered structured questionnaire adapted from the General Beliefs about Medicines Questionnaire (BMQ) and the Medical Adherence Report Scale (MARS) used in studies conducted in Sweden was modified and used for the study [22]. The first section (section A) of the questionnaire elicited socio demographic information, section B dealt with medical and drug history, section $\mathrm{C}$ was about personality traits, section D elicited beliefs about medicines, while section $\mathrm{E}$ measured adherence to medications. All the statements in sections $\mathrm{C}$ to $\mathrm{E}$ were answered on a five-point Likert scale: $1=$ strongly disagree, $2=$ disagree, $3=$ uncertain, $4=$ agree and $5=$ strongly agree.

\subsection{Data Collection}

The questionnaires were administered by 3 research assistants who were trained for 2 days prior to data collection.

\subsection{Data Analysis}

Mean scores were calculated for each participant and for all BMQ sub-parts from one to five. A higher mean indicated a stronger belief in the concept described.

The BFI scale scoring for Personality Trait was used. ("R" denotes reverse-scored items):

Extraversion: 1, 6R, 11, 16, 21R, 26, 31R (Range of Score = 7 - 35);

Agreeableness: 2R, 7, 12R, 17, 22, 27R, 32, 37R, 42 (Range of Score = 9 - 45);

Conscientiousness: 3, 8R, 13, 18R, 23R, 28, 33, 43R (Range of Score $=8$ - 40);

Neuroticism: 4, 9R, 14, 19, 24R, 29, 34R, 36, 38, 39 (Range of Score = 10 - 50);

Openness: 5, 10, 15, 20, 25, 30, 35R, 40, 41R, 44 (Range of Score = 10 - 50).

The Beliefs About Medication Questionnaire (BMQ) had two sections; BMQ Specific which had Necessity Belief with three items and Concern Belief with five items; BMQ General had Harm Belief with two items, overuse belief with two items and Benefit Belief with one item. Each item is scored 1 for a positive response and 0 for a negative response.

The Medication Adherence Report Scale that was adapted had 6 items with Yes/No responses. Each positive response attracted one point while negative responses attracted zero. A total score less than 75\% (4.5/6) was regarded as being non-adherent [23].

Statistical analysis was conducted using Epi Info Software Version 3.5.1 (August 2008). Associations between proportions were determined using the chi square test, while differences in means were assessed using the Student's test statistic. Relationships between Personality trait score, Medication Belief Score and Adherence scores were determined using Pearson's correlation coefficient statistic. Tests of significance were performed using a $95 \%$ confidence interval with the level of significance set at $P<0.05$. 
Data were summarized and key variables described. Outcome measures included personality traits, patients' medication beliefs, medication adherence rates, and associations between the traits, beliefs and adherence rates.

\subsection{Ethical Considerations}

Ethical clearance was obtained from the Health Research and Ethics Committee (HREC) of the Lagos State University Teaching Hospital, permission was obtained from the Chief Medical Director of LASUTH and the Consultants in charge of the clinic. In addition, respondents were also assured of the confidentiality of data collected and were provided the option of withdrawal at any point during the survey without any consequence on their management.

\subsection{Consent Procedure}

Informed written consent was obtained from each respondent prior to data collection with the aid of a consent form.

\subsection{Study Limitations}

Information obtained may be subject to courtesy and recall biases.

\section{Results}

A total number of 223 respondents were recruited into the study having met the inclusion criteria. The mean age of respondents in this study was 61.4 years. The Majority of the respondents $139(62.3 \%)$ were females, male: female ratio was $1: 1.7$. Most of the respondents (70.4\%) were married and about $21 \%$ were widowed. All the respondents had at least primary education. Thirty five percent had tertiary and postgraduate education. About $85 \%$ of respondents earned at least N 20,000 per month and the Median income of respondents was N 40,000 (Table 1).

Most of the respondents (87.4\%). had been diabetic for more than 2 years (48 months) with an average disease period of 10.3 years (123.0 months). Also, the average period of treatment for diabetes was 9.2 years (111.0 months). More than $58 \%$ of the participants had a co morbidity; mostly hypertension in about $91 \%$ of cases. More than two thirds (63.7\%) of respondents were on more than three drugs at a time (Table 2).

The mean score for agreeable, conscientious, extraversion, neuroticism and openness personality traits among the respondents were 34.2, 31.1, 23.4, 26.7 and 34.3 respectively; While the mean score for necessity, concern, harm, overuse \& benefit beliefs among respondents were 9.0, 11.3, 4.2, 6.2 and 4.2 respectively (Table 5). The description and range of scores in the scales are outlined in the methodology.

On adherence, $37.2 \%$ of respondents reported they sometimes forget to take their drugs, while $28.7 \%$ sometimes decide to miss out a dose. About $72 \%$ of the participants reported they did not take their drugs a day before. Overall, $59.2 \%$ of respondents were adherent to their treatment while $40.8 \%$ were not. The mean total adherence score was 4.6 (Table 3 and Table 4).

There was no statistically significant association between the age, marital status, level of education \& adherence to medication in this study. However, there was a statistically significant association between the gender of respondents and adherence to medication. A higher proportion of males $(70.2 \%)$ were more likely to adhere to their medication compared to females $(52.5 \%)$, and this was statistically significant $(P<0.05)$ (Table 1$)$.

There was no statistically significant association between the duration of being diabetic, duration of treatment, presence of a co morbidity and adherence to medication $(P>0.05)$. Although, a higher proportion $(62.7 \%)$ of respondents who were on more than three medications were adherent compared to those on three or less number of medications (51.9), this was not statistically significant $(P>0.05)$ (Table 2).

There was a statistically significant difference in the mean neuroticism personality trait score of adherent compared to non-adherent respondents. The non-adherent respondents had a higher mean score of neuroticism personality (27.6) compared to adherent respondents $(25.8)$ and this was statistically significant $(P<0.05)$. There was no statistically significant difference in the mean extraversion, openness, agreeable and conscientious personality traits scores of adherent and non-adherent respondents $(P>0.05)$. There was no statistically significant difference in the mean score of adherent and non-adherent respondents with necessity, harm, overuse and benefit medication beliefs $(P>0.05)$. Although the mean concern medication belief of non-adherent respondents was higher (11.8) than the adherent group (11.0), this was however not statistically significant $(P>0.05)$ (Table 5). 
Table 1. Association between socio-demographic \& adherence.

\begin{tabular}{|c|c|c|c|c|c|}
\hline \multirow{2}{*}{ Variable } & \multirow{2}{*}{ Freq (\%) } & \multicolumn{2}{|c|}{ Adherence $(\mathrm{N}=\mathbf{2 2 3})$} & \multirow{2}{*}{ Statistics } & \multirow{2}{*}{$P$ value } \\
\hline & & Non-adherence & Adherence & & \\
\hline \multicolumn{6}{|l|}{ Age (years) } \\
\hline$<30$ & $7(3.1)$ & $2(28.6)$ & $5(71.4)$ & $\chi^{2}=7.7$ & 0.054 \\
\hline $30-40$ & $7(3.1)$ & $5(71.4)$ & $2(28.6)$ & & \\
\hline $40-50$ & $23(10.3)$ & $14(60.9)$ & $9(39.1)$ & & \\
\hline$>50$ & $185(83.1)$ & $70(37.8)$ & $115(62.2)$ & & \\
\hline NR & $1(0.4)$ & & & & \\
\hline Total & $223(100.0)$ & $91(41.0)$ & $131(59.0)$ & & \\
\hline Mean \pm SD & $61.4 \pm 13.1$ & $59.7 \pm 13.2$ & $62.6 \pm 13.0$ & $\mathrm{t}=1.6$ & 0.113 \\
\hline Median (range) & $63.5(15-93)$ & $60.0(13-85)$ & $65.0(12-93)$ & & \\
\hline \multicolumn{6}{|l|}{ Gender } \\
\hline Male & $84(37.7)$ & $25(29.8)$ & $59(70.2)$ & $\chi^{2}=6.8$ & 0.007 \\
\hline Female & $139(62.3)$ & $66(47.5)$ & $73(52.5)$ & & \\
\hline Total & $223(100.0)$ & $91(40.8)$ & $132(59.2)$ & & \\
\hline \multicolumn{6}{|l|}{ Marital status } \\
\hline Single & $9(4.0)$ & $4(44.4)$ & $5(55.6)$ & $\chi^{2}=4.2$ & 0.375 \\
\hline Married & $157(70.4)$ & $66(42.0)$ & $91(58.0)$ & & \\
\hline Widowed & $47(21.1)$ & $20(42.6)$ & $27(57.4)$ & & \\
\hline Separated & $8(3.6)$ & $1(12.5)$ & $7(87.5)$ & & \\
\hline Divorced & $2(0.9)$ & $0(0.0)$ & $2(100)$ & & \\
\hline Total & $223(100.0)$ & $91(40.8)$ & $132(59.2)$ & & \\
\hline \multicolumn{6}{|l|}{ Educational level } \\
\hline Primary & $58(26.0)$ & $21(36.2)$ & $37(63.8)$ & $\chi^{2}=1.5$ & 0.675 \\
\hline Secondary & $63(28.3)$ & $29(46.0)$ & $34(54.0)$ & & \\
\hline Tertiary & $53(23.8)$ & $20(37.8)$ & $33(62.2)$ & & \\
\hline Postgraduate & $25(11.2)$ & $11(44.0)$ & $14(56.0)$ & & \\
\hline NR & $24(10.8)$ & & & & \\
\hline Total & $223(100.0)$ & $81(40.7)$ & $118(59.3)$ & & \\
\hline \multicolumn{6}{|l|}{ Household income } \\
\hline$<20,000$ & $33(14.8)$ & $12(36.4)$ & $21(63.6)$ & $\chi^{2}=1.5$ & 0.689 \\
\hline $20,000-50,000$ & $102(45.7)$ & $44(43.1)$ & $58(56.9)$ & & \\
\hline $51,000-100,000$ & $34(15.2)$ & $17(50.0)$ & $17(50.0)$ & & \\
\hline$>100,000$ & $11(4.9)$ & $4(36.4)$ & $7(63.6)$ & & \\
\hline NR & $43(19.3)$ & & & & \\
\hline Total & $223(100.0)$ & $77(42.8)$ & $103(57.2)$ & & \\
\hline Mean \pm SD & & $51,402.6 \pm 54,041.7$ & $49,789.3 \pm 44,040.9$ & $\mathrm{t}=0.2$ & 0.826 \\
\hline Median & 40,000 & 30,000 & 40,000 & & \\
\hline
\end{tabular}

NR: Non Response. 
Table 2. Association between drug history \& adherence.

\begin{tabular}{|c|c|c|c|c|c|}
\hline \multirow{2}{*}{ Variable } & \multirow{2}{*}{ Freq (\%) } & \multicolumn{2}{|c|}{ Adherence } & \multirow{2}{*}{ Statistics } & \multirow{2}{*}{$P$ value } \\
\hline & & Non-adherence & Adherence & & \\
\hline \multicolumn{6}{|l|}{ Duration of being diabetic (months) } \\
\hline $6-12$ & $10(4.5)$ & $5(50.0)$ & $5(50.0)$ & $\chi^{2}=3.1$ & 0.371 \\
\hline $13-24$ & $18(8.1)$ & $7(38.9)$ & $11(61.1)$ & & \\
\hline $25-48$ & $36(16.1)$ & $19(52.8)$ & $17(47.2)$ & & \\
\hline$>48$ & $159(71.3)$ & $60(37.8)$ & $99(62.2)$ & & \\
\hline Total & $223(100.0)$ & $91(40.8)$ & $132(59.2)$ & & \\
\hline Mean \pm SD & $123.0 \pm 98.5$ & $121.5 \pm 101.9$ & $124.3 \pm 96.6$ & $\mathrm{t}=0.2$ & 0.834 \\
\hline Median & 96.0 & 84.0 & 96.0 & & \\
\hline \multicolumn{6}{|l|}{ Duration on treatment (month) } \\
\hline $6-12$ & $13(5.8)$ & $7(53.8)$ & $6(46.2)$ & $\chi^{2}=3.9$ & 0.270 \\
\hline $13-24$ & $23(10.3)$ & $7(30.4)$ & $16(69.6)$ & & \\
\hline $25-48$ & $37(16.6)$ & $19(51.4)$ & $18(48.6)$ & & \\
\hline$>48$ & $150(67.3)$ & $58(38.7)$ & $92(61.3)$ & & \\
\hline Total & $223(100.0)$ & $91(40.8)$ & $132(59.2)$ & & \\
\hline Mean \pm SD & $111.0 \pm 92.0$ & $106.6 \pm 91.1$ & $114.1 \pm 93.1$ & $\mathrm{t}=0.6$ & 0.352 \\
\hline Median & 84.0 & 72.0 & 84.0 & & \\
\hline \multicolumn{6}{|l|}{ Co-morbidity } \\
\hline Yes & $131(58.7)$ & $54(41.2)$ & $77(58.8)$ & $\chi^{2}=0.1$ & 0.454 \\
\hline No & $79(35.4)$ & $34(43.0)$ & $45(57.0)$ & & \\
\hline NR & $13(5.8)$ & & & & \\
\hline Total & $223(100.0)$ & $88(41.9)$ & $122(58.1)$ & & \\
\hline \multicolumn{6}{|l|}{ No. of medications on } \\
\hline 1 & $12(5.4)$ & $6(50.0)$ & $6(50.0)$ & $\chi^{2}=2.3$ & 0.302 \\
\hline $2-3$ & $65(29.1)$ & $31(47.7)$ & $34(52.3)$ & & \\
\hline$>\mathbf{3}$ & $142(63.7)$ & $53(37.3)$ & $89(62.7)$ & & \\
\hline NR & $4(1.8)$ & & & & \\
\hline Total & $223(100.0)$ & $89(40.8)$ & $129(59.2)$ & & \\
\hline Mean No. of medications \pm SD & $4.5 \pm 4.3$ & $4.7 \pm 6.4$ & $4.4 \pm 1.8$ & $\mathrm{t}=0.6$ & 0.581 \\
\hline
\end{tabular}

Table 3. Adherence to medication among respondents.

\begin{tabular}{|c|c|c|c|}
\hline Adherence to medication $(\mathrm{N}=\mathbf{2 2 3})$ & Yes & No & NR \\
\hline Sometimes, I forget to take my medicine & $83(37.2)$ & $136(61.0)$ & $4(1.8)$ \\
\hline Sometimes, I alter the dose of my medicine & $53(23.8)$ & $166(74.4)$ & $4(1.8)$ \\
\hline I stopped taking my medicines for a while & $53(23.8)$ & $166(74.4)$ & $4(1.8)$ \\
\hline Sometimes, I decide to miss out a dose & $64(28.7)$ & $155(69.5)$ & $4(1.8)$ \\
\hline Sometimes, I take less than instructed & $29(13.0)$ & $190(85.2)$ & $4(1.8)$ \\
\hline Did you take your drug yesterday & $160(71.7)$ & $59(26.5)$ & $4(1.8)$ \\
\hline
\end{tabular}


Table 4. Medication adherence scores.

\section{Frequency $(\mathrm{N}=\mathbf{2 2 3})$ (percent)}

\section{Adherence}

Non-adherence

Adherence

Adherence score

Mean \pm SD

$4.6 \pm 1.5$

Median (range)

$5.0(0-6)$

Table 5. Means Score of patients' personality traits, beliefs about medicines (BMQ), comparing non-adherent with adherent patients.

\begin{tabular}{|c|c|c|c|c|c|}
\hline \multirow{2}{*}{ Variables } & \multirow{2}{*}{ Total mean score \pm SD } & \multicolumn{2}{|c|}{ Scale score means $(\mathrm{SD})(\mathrm{n}=\mathbf{2 2 3})$} & \multirow{2}{*}{ t test } & \multirow{2}{*}{$P$ value } \\
\hline & & Non-adherence & Adherence & & \\
\hline \multicolumn{6}{|l|}{ Personality trait } \\
\hline Neuroticism & $26.7 \pm 4.7$ & $27.6 \pm 5.0$ & $25.8 \pm 4.4$ & 2.6 & 0.011 \\
\hline Extraversion & $23.4 \pm 3.8$ & $23.1 \pm 3.5$ & $23.6 \pm 3.9$ & 0.9 & 0.375 \\
\hline Conscientiousness & $31.1 \pm 3.7$ & $31.0 \pm 3.8$ & $31.1 \pm 3.7$ & 0.2 & 0.814 \\
\hline Openness & $34.3 \pm 5.0$ & $34.3 \pm 5.2$ & $34.3 \pm 4.9$ & 0.0 & 0.980 \\
\hline Agreeableness & $34.2 \pm 4.3$ & $34.3 \pm 4.7$ & $34.2 \pm 4.1$ & 0.1 & 0.891 \\
\hline \multicolumn{6}{|l|}{ Medication belief } \\
\hline \multicolumn{6}{|l|}{ BMQ specific } \\
\hline Necessity & $9.0 \pm 2.2$ & $8.8 \pm 2.3$ & $9.1 \pm 2.2$ & 0.9 & 0.347 \\
\hline Concern & $11.3 \pm 3.2$ & $11.8 \pm 3.1$ & $11.0 \pm 3.2$ & 1.8 & 0.078 \\
\hline \multicolumn{6}{|l|}{ BMQ general } \\
\hline Harm & $4.2 \pm 1.9$ & $4.4 \pm 2.1$ & $4.1 \pm 1.8$ & 1.0 & 0.331 \\
\hline Overuse & $6.2 \pm 2.2$ & $6.5 \pm 2.2$ & $6.1 \pm 2.2$ & 1.2 & 0.233 \\
\hline Benefit & $4.2 \pm 0.9$ & $4.2 \pm 0.9$ & $4.2 \pm 0.9$ & 0.5 & 0.610 \\
\hline
\end{tabular}

There was a statistically significant but weak negative correlation $(\mathrm{r}=-0.1)$ between neuroticism personality trait and adherence. The higher the neuroticism, the lower the adherence $(P<0.05)$. There was also a statistically significant correlation $(\mathrm{r}=0.2)$ between concern medication belief and adherence to medication. The higher the concern medication belief, the lower the adherence to medication and this was statistically significant $(P<$ 0.05) (Table 6).

\section{Discussion}

We assessed the personality traits, medication beliefs and adherence to anti diabetic treatment among patients attending the Diabetic Clinic of Lagos State University Teaching Hospital Lagos. The mean age of respondents in this study was 61.4 which was similar to what was reported in other studies [6]. Most of the patients on treatment for chronic condition like diabetes are usually in their middle and old age [3]. In this study, the majority of the respondents 139 (62.3\%) were females. As in most other studies, females tend to have better health seeking behaviours than men [6] [8].

The average period respondents in this study had been diabetic was 10.3 years (123 months) and the average 
Table 6. Correlation between respondents' personality traits, medication beliefs and level of adherence.

\begin{tabular}{cccc}
\hline & & Adherence & \\
& $\mathbf{r}$ & F test & P value \\
\cline { 2 - 4 } Personality & -0.1 & 4.8 & 0.049 \\
Neuroticism & 0.1 & 2.8 & 0.094 \\
Extraversion & 0.0 & 0.5 & 0.471 \\
Conscientiousness & 0.0 & 0.5 & 0.492 \\
Openness & 0.0 & 0.1 & 0.805 \\
Agreeableness & & & \\
Medication belief & & & 0.136 \\
BMQ specific & 0.1 & 2.3 & 0.010 \\
Necessity & -0.2 & 6.7 & 0.346 \\
Concern & & & 0.342 \\
BMQ general & 0.0 & 0.9 & 0.769 \\
Harm & 0.0 & 0.9 & \\
Overuse & 0.0 & 0.1 & \\
Benefit & & & \\
\hline
\end{tabular}

period they had been on treatment for diabetes was 9.2 years (111 months). As in most studies, the average period patients had been diabetic was 10 years and above [5]. More than $58 \%$ of respondents from this study had a co morbidity; mostly hypertension in about $91 \%$. This is also comparable with findings from other studies. In an Ethiopian study on Diabetics, more than $61 \%$ of respondents had hypertension as a co-morbidity [24].

The results from this study also showed that $59.2 \%$ of respondents were adherent to their treatment while $40.8 \%$ were not. Proportions of non-adherent patients vary from study to study. A US survey reported that $28 \%$ of patients were non adherent [5], which is similar to findings from a study done in an eastern part of Nigeria which reported a non-adherence rate of $27.5 \%$ [9]. However higher figures of non-adherence $(53.0 \%)$ were recorded in the Malaysian study [6], and another study conducted in the Middle belt of Nigeria which reported that $73.6 \%$ of respondents were not adherent [8].

In this study, there was a statistically significant association between the gender of respondents and adherence to medication. This is similar to the findings of the study done in central Nigeria [8]. However, unlike findings from some other studies, there was no statistically significant association between the respondents' age, marital status, level of education, co morbidity, and duration of being diabetic and adherence to medication in this study [6] [8] [9].

In this study, there is a relationship between higher score in neuroticism personality trait and non-adherence to medication. People with high scores on neuroticism have a higher propensity to display worry, anxiety and vulnerability to stress. In comparison, low scorers on this personality trait are more inclined to have an even-tempered disposition [25]. The behavioural tendencies associated with higher scores on neuroticism may explain the non-adherence behaviour among the respondents in this study. The findings are in line with previous research findings showing associations between higher scores neuroticism and non-adherence to long- term medication treatment [13]. And it is also similar to findings from a study on personality and adherence to antibiotic therapy among the Swedish population [14]. In this study, there was no statistically significant relationship between extraversion, openness, agreeable and conscientious personality traits and non-adherence behaviour of respondents. This finding was at variance with reports from a study on personality and adherence to antibiotic therapy among Swedish population which showed a relationship between agreeableness \& conscientiousness personality traits and adherence to medication [14].

Furthermore, there was association between adherence and beliefs about specific concerns. This is similar to 
findings from a study from the UK on predictors of adherence to secondary preventive treatment after stroke, associations between BMQ-specific (Necessity and Concern) and adherence testing in which statistically significant associations were found with subscale Concern [26]. In another study among patients with rheumatoid arthritis, Concerns scores for non-adherent participants were higher than for the adherent group [27]. Findings from this study also showed that the adherent respondents have higher specific necessity belief and lower general harm \& overuse beliefs which was not statistically significant, but in keeping with findings from other studies [23] [28]. Most studies about medication adherence concluded that negative beliefs about medications could serve as powerful barriers to successful adherence [29]-[31].

\section{Conclusions}

Although methods involved in adherence studies differ, the level of adherence identified in this study is similar to findings from previous studies.

Personality traits of diabetic patients on anti-diabetics can influence their adherence to treatment and patients with neuroticism personality trait particularly tend to be non-adherent to medication. Specific concern medication belief tends to be related to non-adherence to medications and negative medication belief can impair adherence to long-term medications. Concerns about long-term effects of anti-diabetic medications should be addressed by healthcare workers to minimize concerns and consequently improve medication adherence. Also, healthcare providers should also pay more attention to the personality traits of patients, especially those with neuroticism personality during medication counseling.

\section{Acknowledgements}

The authors thank Drs. Abdurraheem-Salami Ibipo and Andrew Airauhi for supervising the data collection process of this study.

\section{References}

[1] Shriastava, S.R., Shrivastava, P.S. and Ramasamy, J. (2013) Role of Self-Care in Management of Diabetes Mellitus. Journal of Diabetes \& Metabolic Disorders, 12, 14. http://dx.doi.org/10.1186/2251-6581-12-14

[2] Bezie, Y., Molina, M., Hernandez, N., Batista, R., Niang, S. and Huet, D. (2008) Therapeutic Compliance: A Prospective Analysis of Various Factors Involved in the Adherence Rate in Type 2 Diabetes. http://www.em-consulte.com/en/article/80533

[3] Ogbera, A.O. and Ekpebegh, C. (2014) Diabetes Mellitus in Nigeria: The Past, Present and Future. World Journal of Diabetes, 5, 905-911. http://dx.doi.org/10.4239/wjd.v5.i6.905

[4] WHO (2015) Adherence to Long-Term Therapies: Evidence for Action [Internet]. http://www.who.int/chp/knowledge/publications/adherence_report/en/

[5] Mann, D.M., Ponieman, D., Leventhal, H. and Halm, E.A. (2009) Predictors of Adherence to Diabetic Medications: The Role of Disease and Medication Beliefs. Journal of Behavioral Medicine, 32, 278-284. http://dx.doi.org/10.1007/s10865-009-9202-y

[6] Ahmad, N.S., Ramli, A., Islahudin, F. and Paraidathathu, T. (2013) Medication Adherence in Patients with Type 2 Diabetes Mellitus at Primary Health Clinics in Malaysia. Patient Preference and Adherence, 7, 525-530.

[7] Yusuff, K.B., Obe, O. and Joseph, B.Y. (2008) Adherence to Anti-Diabetic Drug Therapy and Self Management Practices among Type-2 Diabetics in Nigeria. Pharmacy World \& Science, 30, 876-883. http://dx.doi.org/10.1007/s11096-008-9243-2

[8] Abdulazeez, F.I., Omole, M. and Ojulari, S.L. (2014) Medication Adherence amongst Diabetic Patients in a Tertiary Healthcare Institution in Central Nigeria. Tropical Journal of Pharmaceutical Research, 13, 997-1001. http://dx.doi.org/10.4314/tjpr.v13i6.25

[9] Pascal, I.G.U., Ofoedu, J.N., Uchenna, N.P., Nkwa, A.A. and Uchamma, G.E. (2012) Blood Glucose Control and Medication Adherence among Adult Type 2 Diabetic Nigerians Attending a Primary Care Clinic in Under-Resourced Environment of Eastern Nigeria. North American Journal of Medical Sciences, 4, 310-315. http://dx.doi.org/10.4103/1947-2714.98590

[10] Sjolander, M., Eriksson, M. and Glader, E.-L. (2013) The Association between Patients' Beliefs about Medicines and Adherence to Drug Treatment after Stroke: A Cross-Sectional Questionnaire Survey. BMJ, 3, e003551. http://dx.doi.org/10.1136/bmjopen-2013-003551 
[11] Menckeberg, T.T., Bouvy, M.L., Bracke, M., Kaptein, A.A., Leufkens, H.G., Raaijmakers, J., et al. (2008) Beliefs about Medicines Predict Refill Adherence to Inhaled Corticosteroids. Journal of Psychosomatic Research, 64, 47-54. http://dx.doi.org/10.1016/j.jpsychores.2007.07.016

[12] Horne, R. and Weinman, J. (1999) Patients' Beliefs about Prescribed Medicines and Their Role in Adherence to Treatment in Chronic Physical Illness. Journal of Psychosomatic Research, 47, 555-567. http://dx.doi.org/10.1016/S0022-3999(99)00057-4

[13] Bruce, J.M., Hancock, L.M., Arnett, P. and Lynch, S. (2010) Treatment Adherence in Multiple Sclerosis: Association with Emotional Status, Personality, and Cognition. Journal of Behavioral Medicine, 33, 219-227. http://dx.doi.org/10.1007/s10865-010-9247-y

[14] Axelsson, M. (2013) Report on Personality and Adherence to Antibiotic Therapy: A Population-Based Study. BMC Psychology, 1, 24. http://dx.doi.org/10.1186/2050-7283-1-24

[15] Horne, R., Weinman, J. and Hankins, M. (1999) The Beliefs about Medicines Questionnaire: The Development and Evaluation of a New Method for Assessing the Cognitive Representation of Medication. Psychology \& Health, 14, 124. http://dx.doi.org/10.1080/08870449908407311

[16] Legal Notice on Publication of the Details of the Breakdown of the National and State Provisional Totals 2006 Census. Federal Republic of Nigeria Official Gazette (2007) http://www.nigerianstat.gov.ng/Connections/Pop2006.pdf

[17] LASUTH: In Pursuit of Unparalleled Health Care Delivery (2008)

[18] About LASUTH. Lagos State University Teaching Hospital (2010) http://www.lasuth.org/

[19] Srivastava, S. (2015) Measuring the Big Five Personality Domains. http://pages.uoregon.edu/sanjay/bigfive.html

[20] Schacter, D.S., Gilbert, D.T. and Wegner, D.M. (2011) Psychology. 2nd Edition, Worth, New York, 474-475.

[21] John, O.P. and Srivastava, S. (1999) The Big-Five Trait Taxonomy: History, Measurement, and Theoretical Perspectives. In: Pervin, L.A. and John, O.P., Eds., Handbook of Personality: Theory and Research, Guilford Press, New York, 102-138.

[22] Mardby, A. (2008) General Beliefs about Medicines among Pharmacy Clients, Healthcare Students and ProfessionalsGroup Differences and Association with Adherence. Intellecta DocuSys AB, Västra Frölunda, Sweden, 13-21.

[23] Alhewiti, A. (2014) Adherence to Long-Term Therapies and Beliefs about Medications. International Journal of Family Medicine, 2014, Article ID: 479596. http://www.pubmedcentral.nih.gov/articlerender.fcgi?artid=3943193\&tool=pmcentrez\&rendertype=abstract

[24] Nasir, T.W., Mulugeta, T.A. and Sadikalmahdi, H. (2011) Medication Adherence in Diabetes Mellitus and Self Management Practices among Type 2 Diabetics in Ethiopia. North American Journal of Medical Sciences, 3, 418-423.

[25] Costa Jr., P.T. and McCrae, R.R. (1992) Revised NEO Personality Inventory (NEO-PI-R) and NEO Five-Factor Inventory (NEO-FFI) Professional Manual. Psychological Assessment Resources, Odessa.

[26] O'Carroll, R., Whittaker, J., Hamilton, B., et al. (2011) Predictors of Adherence to Secondary Preventive Medication in Stroke Patients. Annals of Behavioral Medicine, 41, 383-490. http://dx.doi.org/10.1007/s12160-010-9257-6

[27] Neame, R. (2005) Beliefs about Medications: A Questionnaire Survey of People with Rheumatoid Arthritis. Rheumatology, 44, 762-767. http://www.rheumatology.oupjournals.org/cgi/doi/10.1093/rheumatology/keh587 http://dx.doi.org/10.1093/rheumatology/keh587

[28] Phatak, H.M. and Thomas III, J. (2006) Relationship between Beliefs about Medications and Nonadherence to Prescribed Chronic Medications. Annals of Pharmacotherapy, 40, 1737-1742. http://dx.doi.org/10.1345/aph.1H153

[29] Gatti, M.E., Jacobson, K.L., Gazmararian, J.A., Schmotzer, B. and Kripalani, S. (2009) Relationships between Beliefs about Medications and Adherence. American Journal of Health-System Pharmacy, 66, 657-664. http://dx.doi.org/10.2146/ajhp080064

[30] Iihara, N., Tsukamoto, T., Morita, S., Miyoshi, C., Takabatake, K. and Kurosaki, Y. (2004) Beliefs of Chronically Ill Japanese Patients That Lead to Intentional Non-Adherence to Medication. Journal of Clinical Pharmacy and Therapeutics, 29, 417-424. http://dx.doi.org/10.1111/j.1365-2710.2004.00580.x

[31] Mardby, A.C., Akerlind, I. and Jorgensen, T. (2007) Beliefs about Medicines and Self-Reported Adherence among Pharmacy Clients. Patient Education and Counseling, 69, 158-164. http://dx.doi.org/10.1016/j.pec.2007.08.011 